\title{
Single sternal metastasis due to malignant melanoma with unexpected long-term survival:
}

\section{a case report}

\author{
Apostolos S Gogakos,' \\ Dimitrios Paliouras,' \\ Christos Asteriou,' Thomas \\ Rallis,' Achilleas Lazopoulos,' \\ Fotios Chatzinikolaou, ${ }^{2}$ \\ Athanassios Zissimopoulos, ${ }^{3}$ \\ Drosos Tsavlis, ${ }^{4}$ Katerina \\ Tsirgogianni, ${ }^{4}$ Konstantinos \\ Zarogoulidis, ${ }^{4}$ Konstantinos \\ Porpodis, ${ }^{4}$ Kosmas \\ Tsakiridis, ${ }^{5}$ Georgia \\ Pitsiou, ${ }^{4}$ loannis Kioumis, ${ }^{4}$ \\ llias Karapantzos, ${ }^{6}$ \\ Chrysanthi Karapantzou, ${ }^{6}$ \\ Nikos Sachpekidis, ${ }^{5}$ Paul \\ Zarogoulidis, ${ }^{4}$ Nikolaos \\ Barbetakis' \\ 'Thoracic Surgery Department, \\ ${ }^{2}$ Department of Pathology, Theagenio \\ Cancer Hospital, Thessaloniki, \\ ${ }^{3}$ Nuclear Medicine Department, \\ University General Hospital of \\ Alexandroupolis, Democritus \\ University of Thrace, Alexandroupolis, \\ "Pulmonary Department - Oncology \\ Unit, "G. Papanikolaou" General \\ Hospital, Aristotle University of \\ Thessaloniki, ${ }^{5}$ Cardiothoracic Surgery \\ Department, ${ }^{6}$ Ear, Nose and Throat \\ Department, "Saint Luke" Private \\ Hospital, Panorama, Thessaloniki, \\ Greece
}

Correspondence: Paul Zarogoulidis Pulmonary Department - Oncology Unit, "G. Papanikolaou" General Hospital, Aristotle University of Thessaloniki, Exohi I 100, Thessaloniki 57010, Greece Tel +30 697727 I974

Fax +30 23I 0992424

Email pzarog@hotmail.com
This article was published in the following Dove Press journal:

OncoTargets and Therapy

18 January 2016

Number of times this article has been viewed
Abstract: Metastases from melanoma have a very poor prognosis for the patient. Single metastatic lesions in the sternum due to melanoma are extremely rare. A rare case of a presternal mass in a 56-year-old patient who had undergone excision for malignant melanoma is presented. Review of the patient's history and surgical resection of a single metastatic soft tissue lesion offer the best chance of long-term survival.

Keywords: melanoma, metastasis, chest wall, sternum

\section{Introduction}

Metastases from melanoma have a very poor prognosis for the patient. Soft tissue masses are quite hard to distinguish if they are secondary or primary lesions in a patient with a history of melanoma. In this case report, a 56-year-old male with a history of surgically removed malignant melanoma presented with a presternal lesion that proved to be metastasis from the primary site.

\section{Case presentation}

A 56-year-old male presented with a lesion in the right presternal space, growing progressively in size within 3 months. Apart from the mass, no symptoms or discomforts were present. The patient had undergone resection for malignant melanoma of the left tibia 4 years ago, rated Grade IV according to Clark, with $3 \mathrm{~mm}$ thickness according to Breslow. ${ }^{1}$ Sentinel lymph node dissection was negative for metastasis. Microscopic report indicated nevoid melanoma with tumor infiltrating lymphocytes "non-brisk" and a mitotic rate at $0-11 \mathrm{~mm}^{2}$. No ulceration or microsatellitosis was reported. Resection margin was free of neoplastic tissue. Two years later, the patient underwent a second resection for two new lesions at the left tibia, which turned out to be metastases of the original melanoma. Immunohistochemistry was positive for Melan A, S-100 protein, vimentin, and HMB45, while it was negative for PanCK and the epithelial membrane antigen (EMA).

Clinical examination upon admission demonstrated a swelling at the right presternal space, adjacent to the manubrium. On palpation, the lesion was hard and immobile, and there was no tenderness or pain of the sternum or the adjacent ribs. On percussion, there were no pathological findings. No lymphadenopathy was present and the findings from the examination of other organs and systems were normal. He was not under any medication. A plain chest radiograph and posterior-anterior and lateral views showed a lesion at the right side of the manubrium, at the height of sixth intercostals space. Findings from the lungs, the pleura, and the hilum lymph 


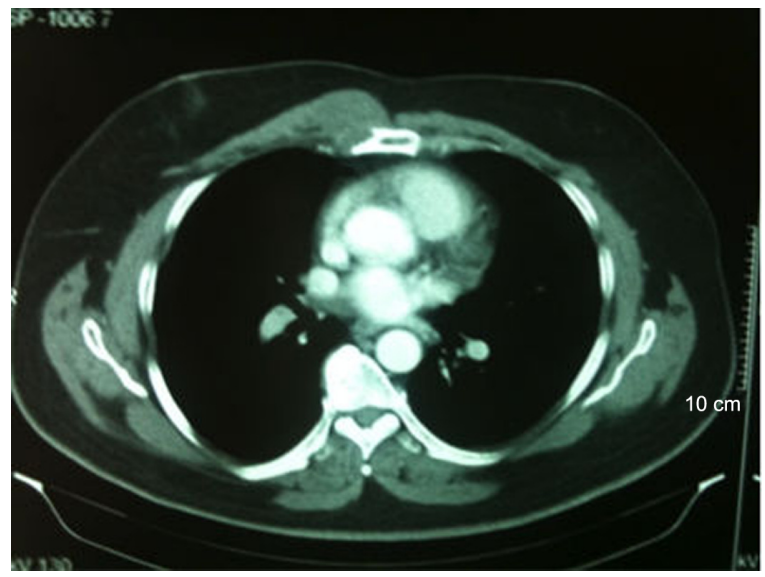

Figure I Chest CT showing the lesion. Abbreviation: CT, computed tomography.

nodes were normal. Laboratory findings of the patient were within normal limits, except a slightly elevated serum calcium rate $(10.26 \mathrm{mg} / \mathrm{dL})$. A chest computed tomography (CT) demonstrated thickness of the pleura anteriorly, at the right side, near the heart (Figure 1). The patient underwent biopsy of the lesion, which was conclusive for a metastatic melanoma.

Staging was completed with brain, abdomen, and a new thorax computed tomography scan prior to surgery, which showed no new findings. Surgical management required a median sternotomy with an extension to the right thoracic wall. The tumor was excised en-bloc with part of the manubrium and parts of the ribs and costochondral joints adjacent to it (fifth, sixth, seventh) (Figure 2A). The defect was covered with a mesh and the wound was closed in layers over two chest tubes (one in the mediastinum and the other in the right pleural cavity) connected to a thoracic drainage device (Bülau) (Figure 2B).

A

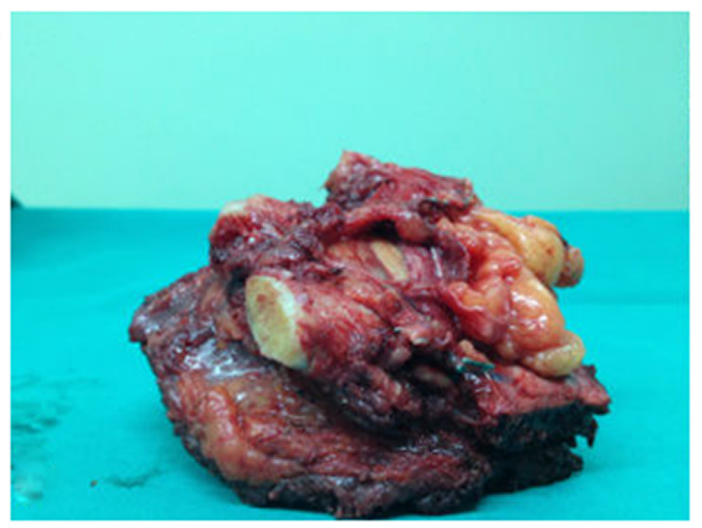

The patient was hospitalized in our ICU for the first 24 hours post-surgery and was fully conscious. Three days post-surgery, the patient presented with pneumothorax at the right side, which was treated with placement of a new chest tube. He was discharged 14 days later after the removal of all tubes. Pathology was consistent with malignant melanoma, which infiltrated the muscles of the thoracic wall and sternum. Immunohistochemistry was positive for Melan A, S-100 protein, and HMB45, while it was negative for PanCK, CK-7, CK-20, TTF-1 and epithelial membrane antigen. The surgical margins were free of neoplastic tissue. During his follow-up 2 weeks later, the wound had healed well and the patient had no symptoms (Figure 3). Four years later, the patient was free of both local and distant recurrence.

\section{Discussion}

Metastatic melanoma has a very poor prognosis, with a median survival of only 6-8 months. ${ }^{2}$ Today, the use of newer and more effective therapeutic regimens help in the early detection of metastatic melanoma. ${ }^{3}$

In this case report, a 56-year-old male with a history of surgically removed malignant melanoma was presented with a presternal lesion that proved to be a metastasis from the primary site. It is quite common for the metastases of cutaneous malignant melanoma of ordinary type to resemble various types of soft tissue sarcoma. However, thorough immunohistological analysis should be performed to detect the presence of melanin, melanosomes, S-100 protein, Melan A, and HMB45 in order to categorize such tumors as melanoma metastases rather than soft tissue sarcomas. ${ }^{4-7}$

This case study emphasizes the rarity of such occurrence, with a single soft tissue metastasis from malignant melanoma. Although prognosis in such cases is poor, review

B

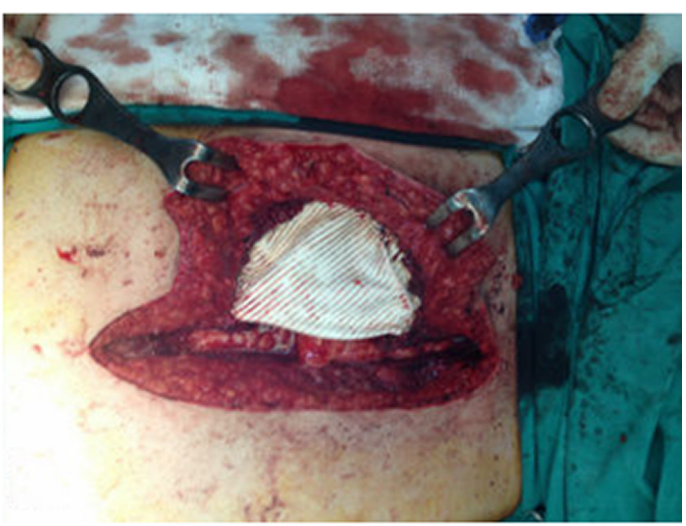

Figure 2 Surgical evidence.

Notes: (A) The tumor excised en-bloc with part of the adjacent ribs and manubrium. (B) The mesh covering the defect before closure of the surgical wound. 


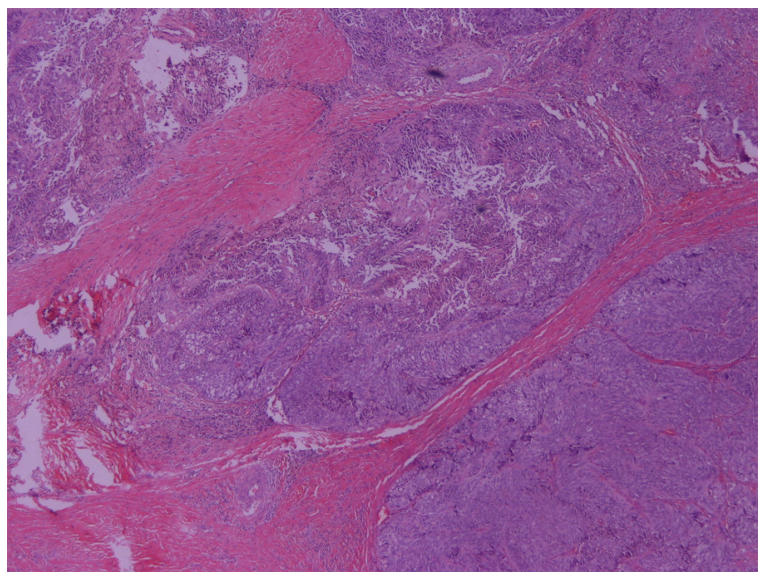

Figure 3 Metastatic melanoma, H\&E stain, $\times 40$.

Abbreviation: H\&E stain, hematoxylin and eosin stain.

of the literature indicates that surgical removal of a single metastatic lesion results in a better survival rate compared to other therapeutic approaches, such as immunotherapy or radiation. ${ }^{4,5}$

Based on this study, we concluded that patients with oligometastatic disease do benefit if the lesions are surgically removed. Preoperative evaluation of the number of lesions though remains crucial. A careful review of the patient's history, along with early diagnosis and radical surgery, is essential for a favorable outcome, offering the best chance of long-term survival.

\section{Acknowledgment}

We thank the patient who provided written informed consent to publish this paper and the accompanying images. A copy of the written consent is available for review by the Editor-in-chief of this journal. Ethical approval for this study was obtained from the review board of the Theagenio Cancer Hospital.

\section{Disclosure}

The authors declare no conflict of interest.

\section{References}

1. Balch CM, Soong SJ, Gershenwald JE, et al. Prognostic factors analysis of 17,600 melanoma patients: Validation of the American Joint Committee on Cancer melanoma staging system. J Clin Oncol. 2001; 19(16):3622-3634.

2. Tafra L, Dale PS, Wanek LA, Ramming KP, Morton DL. Resection and adjuvant immunotherapy for melanoma metastatic to the lung and thorax. J Thorac Cardiovasc Surg. 1995;110(1):119-128.

3. Chen JT, Dahmash NS, Ravin CE, et al. Metastatic melanoma in the thorax: report of 130 patients. Am J Roentgenol. 1981;137(2):293-298.

4. Barth A, Wanek LA, Morton DL. Prognostic factors in 1,521 melanoma patients with distant metastases. J Am Coll Surg. 1995;181:193-201.

5. Fletcher WS, Pommier RF, Lum S, et al. Surgical treatment of metastatic melanoma. Am J Surg. 1998;175:413-417.

6. Dewan M, Malatani TS, Ansari MA. Lessons to be learned: a case study approach. Malignant melanoma of soft tissue. J R Soc Promot Health. 2005;125(1):42-46.

7. Lodding P, Kindblom LG, Angervall L. Metastases of malignant melanoma simulating soft tissue sarcoma. A clinico-pathological, lightand electron microscopic and immunohistochemical study of 21 cases. Virchows Arch A Pathol Anat Histopathol. 1990;417(5):377-388.

\section{Publish your work in this journal}

OncoTargets and Therapy is an international, peer-reviewed, open access journal focusing on the pathological basis of all cancers, potential targets for therapy and treatment protocols employed to improve the management of cancer patients. The journal also focuses on the impact of management programs and new therapeutic agents and protocols on

\section{Dovepress}

patient perspectives such as quality of life, adherence and satisfaction. The manuscript management system is completely online and includes a very quick and fair peer-review system, which is all easy to use. Visit http://www.dovepress.com/testimonials.php to read real quotes from published authors. 